\title{
O TERRITÓRIO NA PERSPECTIVA DAS DIMENSÕES SIMBÓLICAS, CULTURAIS E IDENTITÁRIAS
}

\author{
José Antônio de Sousa ${ }^{1}$
}

\section{RESUMO}

Este artigo é fruto de uma pesquisa cuja base metodológica ancora-se em revisões bibliográficas acerca do território, como sendo o objeto principal de análise. O objetivo foi analisar o território na perspectiva de suas dimensões simbólicas no universo da cultura, o qual se encontra também entrelaçado perfeitamente como a questão da identidade. Assim se faz necessário inserir nessas discussões o conceito de território como instrumento categórico que nos auxilia na compreensão da localização, dinâmica e aspectos da cultura dentro de uma espacialidade e suas inter-relações. Sua justificativa fundamenta-se no movimento acadêmico que há em novas reformulações do conceito de território e sua importância para o conhecimento enquanto estratégia no gerenciamento de políticas, a exemplo das políticas culturais. Assim torna-se necessário nesse jogo de aspirações, trabalhar com os conceitos de território, cultura e identidade e as dimensões que estes campos nos apresentam, e que são alvos de intensos debates por diferentes ciências para além das tônicas da ciência geográfica, ganhando assim novos contornos e trazendo em seu bojo uma complexidade e diversidade em suas múltiplas interfaces o que representa a impossibilidade de fixar uma definição, constituindo um amplo leque de diálogos e reflexões sobre o papel do território e os seus campos de investigação, como as manifestações culturais e sua significação. Como resultado, esta pesquisa buscou a compreensão do território enquanto conceito, dimensões simbólicas e suas correspondências a partir das referências analisadas, entre elas os postulados de Milton Santos e Claude Raffestin, na lógica de interpretação dos aspectos e efeitos do processo de globalização, de Hall com a questão das identidades, em Laraia as visões antropológicas, em Geertz a interpretação da cultura pelos seus significados e que nos auxilia a fugir de visões eurocêntricas.

Palavras-chave: Dimensão simbólica. Cultura. Território. Identidade.

\footnotetext{
${ }^{1}$ Licenciado pleno com habilitação em História pela Universidade Salgado de Oliveira UNIVERSO. Especialista em Gestão do Patrimônio Cultural pela Faculdade Metodista Granbery - FMG. Proponente e Coordenador dos projetos: Exposição Fotográfica Passado e Presente: Conhecendo o acervo e a memória arquitetônica macaubense com apoio do Banco do Nordeste - BNB/FUNARTE e do projeto de Inventário do Acervo Arquitetônico do Município de Macaúbas pelo Instituto do Patrimônio Artístico e Cultural da Bahia - IPAC. E-mail: saosilvestre31@gmail.com
} 


\section{ABSTRACT}

This article is based on a survey whose methodological basis is anchored in reviews about territory, as the main object of analysis. The objective was to analyze the territory in view of its symbolic dimensions in the universe of culture, which is also intertwined perfectly as the question of identity. Thus it is necessary to enter these discussions the concept of territory as a categorical tool that helps understanding of the location and dynamic aspects of culture within a spatiality and their interrelations. His rationale is based on academic movement that is in new reformulations of the concept of territory and its importance as a strategy for knowledge management in policies such cultural policies. So it becomes necessary in this game aspirations, working with the concepts of territory, culture and identity and the dimensions that these fields show us, and that are targets of intense debate by different sciences in addition to the tonic of geographical science, thus gaining new contours and bringing with it a complexity and diversity in its multiple interfaces what is the inability to establish a definition, providing a wide range of dialogues and reflections on the role of territory and their fields of research, such as cultural events and its significance. As a result, this study sought to understand the territory as a concept, symbolic dimensions and their correspondences from references analyzed, including the postulates of Milton Santos and Claude Raffestin , the logical interpretation of the aspects and effects of the globalization process, the Hall with the question of identity in Laraia anthropological visions, in Geertz 's interpretation of culture for their meanings and that helps us get away from Eurocentric views .

Keywords: Symbolic Dimension . Culture. Territory. Identity. 


\section{Introdução}

O objeto de investigação deste trabalho é o território, seu desenvolvimento e discussões apoiam-se em pesquisas e revisões bibliográficas específicas e que tangenciam esse objeto. $\mathrm{O}$ objetivo parte em compreender alguns conceitos de território e suas inter-relações na perspectiva das dimensões simbólicas, entrelaçadas as questões da cultura e identidade, como aspectos que fundamentam perfeitamente essas dimensões e suas inter-relações as quais apresentam, via de regra, uma complexidade em sua compreensão, em função do caráter subjetivo das experiências humanas, as quais ficam evidentes no próprio conceito de cultura e identidade.

Temos que considerar que na atualidade a temática do território extrapolou suas visões e o foco tradicional em suas questões meramente físicas como a lógica do espaço, para assim ser interpretado em outras perspectivas fundadas em aspectos mais complexos como o caráter de sua intangibilidade a exemplo do campo cultural com os estudos de outras ciências sociais que aplicam os conceitos de cultura e identidade, por exemplo. Assim o território como pesquisa é alvo de intensos debates por diferentes ciências para além das tônicas da ciência geográfica, ganhando assim novos contornos, conferindo-lhe um melhor entendimento sobre diversas questões, entre elas poderíamos citar as tentativas de caracterizar e classificar as múltiplas dimensões culturais em um determinado território e suas relações com outros territórios de onde aparecem ideias como fronteiras culturais, políticas culturais, diversidade cultural, entre tantas outras.A temática do território a luz do foco de diversas ciências traz em seu bojo uma complexidade e diversidade em suas múltiplas interfaces o que representa a impossibilidade de fixar uma definição, constituindo um amplo leque de diálogos e reflexões sobre o papel do território e os seus campos de investigação, e suas tentativas de compreensão das manifestações culturais e sua significação.

Dessa forma a justificativa para essa pesquisa e reflexão fundamenta-se na compreensão do movimento acadêmico em busca das novas tendências e reformulações do conceito de território e sua importância para o conhecimento enquanto estratégia no gerenciamento de políticas de controle e gestão do espaço e suas diversidades, a exemplo das políticas culturais. Por outro lado pensamos na possibilidade de que quando da incompreensão do território pelas políticas setoriais, ou seja, das intervenções em determinados projetos, estes tendem a gerar os mais diversos tipos de efeitos negativos e controversos, como o engessamento 
de realidades culturais em detrimento de outras, dissonância na aplicação recursos financeiros.

Como resultado, esta pesquisa busca a compreensão do território e alguns de seus conceitos, a identificação de dimensões culturais, simbólica, identitárias e suas correspondências a partir dos referenciais analisados, entre elas os postulados de Milton Santos e Claude Raffestin, na lógica de interpretação dos aspectos e efeitos do processo de globalização, de Hall com a questão das identidades. A ilustração do debate entre Edward Tylor e Laraia com suas visões antropológicas e o conceito de cultura entre as conjunturas do séculos XIX para Taylor e XX para Laraia. Em Geertz encontramos importantes reflexões sobre simbologia e suas significações e que nos ajudam a interpretar a cultura pelos seus significados e códigos, os quais complexos e imersos numa diversidade de acepções, os conceitos de Geertz são interessantes à medida que nos auxilia a fugir de visões eurocêntricas.

Assim num primeiro momento é preciso considerar o panorama histórico-conceitual, da evolução da cultura, tendo como parâmetro sua relação direta e associada com a constituição de processos identitários. Ao trabalharmos com os conceitos de simbologia presente na ótica da semiologia a compreensão da dimensão destes conceitos estreitam nossas reflexões perante suas complexidades, em meio as suas multidimensões, pois no universo da cultura observamos e extraímos algumas de suas interlocuções com distintas áreas do conhecimento e fenômenos sociais, quer seja as relações econômicas, religiosas, suportes tecnológicos, processos diplomáticos da chamada cultura de paz e como fator de compreensão da diversidade do homem no planeta, como se observa os princípios da Declaração Universal dos Direitos Humanos, na Declaração da Diversidade Cultural, e recentemente na Convenção para Promoção e Proteção da Diversidade das Expressões Culturais, dentre tantos outros tratados, convenções e declarações internacionais que objetivam reconhecer, promover e proteger as manifestações culturais.

Dessa forma muito se fala em transversalidade da cultura, ou seja, sua capacidade de potencializar o entendimento de diferentes realidades a partir do caráter de suas interfaces com os mais diferentes ramos científicos, o que a torna uma área bastante complexa. $\mathrm{Na}$ atualidade é cada vez mais crescente o número de artigos, dissertações e teses ancoradas no campo da cultura e nas mais diversas interfaces que a área comporta, como: produção simbólica externada em bens culturais de natureza material e imaterial, a cultura como forma de economia criativa e subsidiária do desenvolvimento sustentável, a cultura como suporte na construção de identidades, ou seja, o termo 'cultura' apresenta para nós 
uma série de conceitos e interfaces multidimensionais. Tal interesse pelo campo da cultura pode ser entendido sobre diversos aspectos políticos, econômicos e sociais, seja pela diversidade e complexidade do tema e por razões em estudar o homem e a sociedade, trazendo para reflexão novas realidades que se processam da relação cultura/território. Tomemos como exemplo a ciência histórica e a revolução científica da historiografia da cultura ou da antropologia cultural. Observamos que à aproximação e o diálogo entre as ciências e, sobretudo as ciências sociais, favorecem uma fluência epistemológica que em conjunto contribuem para construção de novos paradigmas num processo dinâmico cuja abordagem do campo da cultura não se esgota e assim torna-se difícil chegar a uma definição sobre o termo 'cultura'. Uma revisitação no pensamento clássico francês e alemão estreitará nossas visões e concepções que a dimensão da cultura comporta e sua importância como mecanismo de compreensão da relação homem e a sociedade e mais especificamente na perspectiva da lógica do território como espaço simbólico detentor de múltiplas manifestações culturais identitárias, de onde se localiza o universo da cultura e suas interfaces como a identidade cultural.

A seguir trabalhamos com alguns conceitos de território, demarcando assim alguns campo de interpretação e que representam o movimento acadêmico e os seus debates e reflexões, entre eles as concepções de domínio, poder, economia capitalista e efeitos da globalização, e por outros ângulos como as perspectivas das dimensões simbólicas e identitárias e seus significados, assim veremos algumas proposições de autores como: Milton Santos, Haesbaert Costa, Stuart Hall, Laraia, Lobato Corrêa e Claude Raffestin críticos da globalização e teóricos do território, da cultura e identidade.

Depois entramos nos objetivos propriamente ditos desta pesquisa, ou seja, a análise do território enquanto espaço simbólico, que pode ser entendido na perspectiva da dimensão cultural e identitária a qual trataremos no tópico sobre: As dimensões simbólicas, culturais e identitárias do território. O interesse e em específico nesta parte é estreitar nossas visões nestas perspectivas e associá-las a valorização da cultura com enfoque nas dinâmicas de algumas interfaces, dentre elas a questão da identidade, tornando-as mais inteligíveis. Os estudos clássicos em parte sobre o território estão atrelados basicamente à ciência geográfica, quando abarca dentro de sua órbita um conjunto de análises voltadas as questões físicas do espaço, paisagem e lugar e que estão fortemente atrelados ao conceito de território, mas também observamos que os estudos sobre a geografia humana transformou-se nas últimas décadas do século passado no que diz respeito às abordagens e focos em 
questões simbólico-culturais. Outro ponto interessante é a ideia de globalização como fator de transformação das dinâmicas espaciais como se vê nos estudos de Milton Santos quando trabalha com o aspecto das influências negativas da globalização nas "desigualdades sócio espacial”. Outro enfoque interessante é trabalhar com o conceito de simbologia contido na ótica da semiologia como maneira de abordamos e ver o território sobre outro olhar, pois é no território que nascem as expressões culturais genuínas, cada qual com suas práticas, representações e significados conferindo-lhe um caráter de intangibilidade.

Nas considerações finais ao discutir os pontos principais, e os resultados, salienta-se que nestas novas abordagens tem destaque o trabalho conjunto de geógrafos, sociólogos, historiadores e antropólogos cujas leituras paulatinas e multidisciplinares tornam-se cada vez mais dinâmicas, como os diversos recursos de natureza teórico-metodológico e que são necessários para uma afirmação da importância sobre os estudos sobre o território em sua complexidade e na perspectiva de suas dimensões simbólicas e identitárias e sua importância como pesquisa.

\section{A evolução do conceito de cultura e suas dimensões}

Na abordagem do campo cultural e o seu sentido social, nos interessa uma breve evolução conceitual do termo 'cultura'. Para tanto, é necessário incorrer na interpretação que alguns teóricos empreendem em suas discussões, presentes em diversas correntes de pensamento e que são responsáveis pelo alargamento do conceito.

Historicamente a evolução significativa do conceito de cultura reporta ao século XX e vem alargando cada vez mais. Uma das maiores transformações que percebemos é o melhoramento da relação entre cultura erudita e popular, suas diversidades e reconhecimento explicito na dialética da conceituação e suas aplicações sociais de valorização, como no gênero historiográfico da micro história ao abordar lugares e sujeitos até então marginalizados. Não há um padrão de explicação sobre: o que é cultura?Ou seja, não há uma concepção definitiva por ser uma área que carrega em si um caráter orgânico e como tal multidimensional. Segundo o "Dicionário Crítico de Política Cultural: Cultura e Imaginário" organizado por Teixeira Coelho, o termo 'cultura' comporta várias concepções e interpretações que vão sendo apresentadas naturalmente pela construção de uma fluência epistemológica extremamente dinâmica e complexa processada por diferentes ramos das ciências como a filosofa, antropologia e sociologia ao longo da história 
nas práticas teórico-metodológicas e suas pesquisas. Cada ramo científico vai abarcando dentro dessa chamada epistemologia, suas concepções e sentidos, como a concepção de arte, expressão, manifestação e civilização. Essa diversidade de conceitos torna o termo 'cultura' bastante amplo, comportando assim várias explicações, com o auxílio dos quais os cientistas sociais debruçam sobre os modos de criar, viver, suas representações, simbólicas, processos identitários, bem como a afirmação de diferentes grupos sociais e suas etnias nas relações de poder. Assim é interessante reforçar o caráter multidisciplinar desses diversos ramos científicos citados acima.

\footnotetext{
Cultura em sentido amplo remete à ideia de uma forma que caracteriza o modo de vida de uma comunidade em seu aspecto global, totalizante. Num sentido mais estrito, designa o processo de cultivo da mente, nos termos de uma terminologia moderna e cientificista, ou do espírito, para adotar um ângulo mais tradicional. (TEXEIRA COELHO, 1997, p.102)
}

Historicamente, a cultura é um aspecto social intrínseco à vida do homem desde o seu surgimento na terra, nos seus modos de fazer e viver. O que resolvemos colocar então aqui como análise é a evolução do conceito de cultura, para tanto nossa visão aqui é geral, sobretudo a partir da era moderna com o advento das ciências humanas. É sabido por nós que cultura emana do espírito humano e como tal é inerente a sua própria vida. Assim a palavra 'cultura' aparece desde a antiguidade e sua acepção tradicional tem uma conotação ligada principalmente à filosofia, arte e a agricultura sendo difundidos, identificada e classificada ao longo dos períodos históricos e como tal, têm sido produto de análise historiográfica, filosófica, antropológica e outras. Ilustramos que com o advento no final da idade média do pré-renascimento emanado do estilo gótico, a humanidade irá presenciar no século XV uma grande transformação no campo das artes, sobretudo nas áreas da pintura, escultura e arquitetura enriquecendo assim o fazer cultural e social do homem, que será impulsionado pelo crescimento e difusão da corrente humanista via antropocentrismo, adentrando no século XVI. Assim o termo cultura passa a ter um caráter de sentido não só espiritual, mas também de modo racional, de modo que a produção artística então passa a criar uma série de movimentos culturais vanguardistas, além do gótico, surge o barroco e outros estilos cujo racionalismo clássico retoma o classicismo greco-romano e contrapõe ao período medieval, abrindo então o caminho para Idade Moderna. O século XVII é marcado pela valorização do estilo barroco que se traduz nas contradições entre o obscurantismo e iluminismo. No XVIII, temos uma retomada e incorporação das ideias renascentistas, onde o campo das artes, letras, filosofia, desencadeará um contexto conhecido como "século das luzes" 
que são impulsionados pelos cientistas do renascimento e agora integrados ao movimento iluminista.

O movimento iluminista foi um período febril, importante para a produção cultural, desse período podemos destacar a tradição francesa do conceito de cultura que herda uma rica tradição de valores iluministas, como a ideia de razão e civilização, cujo progresso social estaria ligado ao espírito intelectual do homem de onde emana a produção cultural, assim para os franceses o desenvolvimento da cultura está intimamente associada ao progresso, sua evolução e como tal ao ideário de civilização está atrelado aos saberes acumulados. Paradoxalmente o atraso se explicava devido a condição de ignorância ao processo educacional do homem, essas ideias estão também associadas à concepção de nação, universalismo perante a uma unidade, diferente da concepção alemã que veremos a frente. Já no século XIX a palavra cultura ocupa um espaço importante no meio acadêmico sendo analisados por sociólogos, antropólogos, historiadores, cujo conjunto de tratados recebem uma conotação do ponto de vista de civilização, cuja influência encontra-se, por exemplo, na corrente etnocêntrica.É no século XIX que se desenvolve na tradição francesa uma concepção de cultura, discutido, por exemplo, por EdwardTylor(LARAIA, 1986, p.14opcit Taylor) que definiu a cultura de uma forma mais integral em relação aos iluministas, como "complexo que inclui os conhecimentos, as crenças religiosas, a arte, a moral, os costumes e todas as outras capacidades e hábitos da sociedade". Ele reforça ainda que o homem "se adapta ao meio a partir de mecanismos extrabiológicos, diferente dos animais" (LARAIA, 1986, p.15 op. Cit. Taylor). A evolução do conceito de cultura nada mais é do que a evolução social do homem. No início do século XX, a antropologia analisa o aspecto cultural em diferentes sociedades, desde as tribais até as contemporâneas, no sentido de expor e discutir a transmissão do desenvolvimento social e a complexidade da vida via cultura. $\mathrm{O}$ conceito de cultura no viés antropológico apresenta a cultura como sistema adaptativo em diferentes modos de vida, sistema cognitivo onde a cultura é interpretada do ponto de vista do conhecimento sua produção e reprodução na sociedade e irá se contrapor as concepções civilizatórias do século XIX.

Cabe aqui ressaltar a tradição alemã da concepção de cultura que segundo Nobert Elias está contido de modo geral no conceito de kultur, de onde se resume a cultura a fatos intelectuais, artísticos e religiosos impressos na produção cultural. Dessa forma os produtos como: livros, obras de arte representam o fazer cultural do individuo que é particular e de concepções diferentes, enquanto que os franceses assumem a concepção de cultura como civilização de nação e de modo universal, 
para os alemães a cultura é o que diferencia o homem, e desta forma edifica povos com distintas concepções, dessa maneira interpretamos que a concepção francesa é conservadora e um tanto utópica, enquanto que para os alemães pode ser visto com uma interpretação mais racional. A citação a seguir de Nobert Elias sintetiza as diferenças entre os conceitos de cultura nas tradições francesa e alemã:

\begin{abstract}
Até certo ponto, o conceito de civilização minimiza as diferenças nacionais entre os povos: enfatiza o que é comum a todos os seres humanos ou - na opinião dos que o possuem - deveria sê-lo (...) Em contraste, o conceito alemão de Kultur dá ênfase especial a diferenças nacionais e à identidade particular de grupos (...) Enquanto o conceito de civilização inclui a função de dar expressão a uma tendência continuamente expansionista de grupos colonizadores, o conceito de Kultur reflete a consciência de si mesma: Qual é, realmente, a nossa identidade? A orientação do conceito alemão de cultura, com sua tendência à demarcação e ênfase em diferenças e no seu detalhamento, entre grupos, corresponde a este processo histórico (ELIAS, 1994, p.25).
\end{abstract}

Retomando o pensamento do antropólogo Roque de Barros Laraia em suas explicações sobre "Cultura, um conceito antropológico" analisa diversas correntes na evolução do conceito antropológico de cultura, como a de Taylor, que os aspectos biológico e ambiental não são determinantes nas diferenças culturais. Essas constatações foram feitas comparando essas correntes em meio à diversidade cultural dos povos, lugares e a relação do homem com o lugar, que são semelhantes, porém construindo modos de vida diferentes, a exemplo dos iglus e esquimós nessa relação entre meio, interação e concepção cultural (LARAIA, 1986, p.11).

O homem é o resultado do meio cultural em que foi socializado. Ele é um herdeiro de um longo processo acumulativo, que reflete o conhecimento e a experiência adquiridas pelas numerosas gerações que o antecederam. A manipulação adequada e criativa desse patrimônio cultural permite as inovações e as invenções. As diferenças existentes entre os homens, portanto, não podem ser explicadas em termos das limitações que lhes são impostas pelo seu aparato biológico ou pelo seu meio ambiente. (LARAIA, 1986, p.14).

Analisamos até aqui a evolução do conceito de cultura a partir de um sucito e $\operatorname{logo}$ superficial panorama histórico orientado pela clássica divisão historiográfica e pela história da arte, no intuito de focar alguns períodos importantes. Paulatinamente extrai-se dessa evolução o pensamento de alguns teóricos. Inicialmente buscamos referência no Dicionário Crítico de Política Cultural organizado por Teixeira Coelho, a seguir ilustramos uma síntese do embate antropológico tradicional e moderno respectivamente entre Taylor e Laraia. Outra referência importante no campo da cultura na atualidade são as reflexões do 
sociólogo Nobert Elias abordando as concepções entre Estado e processo civilizatório na perspectiva das sociedades vistas como um "sistema social” (NOBERT ELIAS, 1994, p. 156/57). Em Nobert Elias selecionamos suas indagações sobre a tradição da concepção de cultura entre franceses e alemães. Dessa maneira em parte podemos observar o quanto à cultura comporta a ideia de pluralidade dadas as suas dimensões sociais, econômicas e políticas no meio social.

A respeito das dimensões que tornam a cultura uma ideia plural, veremos algumas possibilidades de análises, de algumas de suas interfaces tomando de empréstimo o conceito de simbologia trabalhado por Clifford Geertz, quando procura interpretar as culturas. Utilizaremos assim o conceito de simbologia como parâmetro para analisar as dimensões culturais, simbólicas e identitárias na perspectiva do território, com espaço simbólico e detentor de símbolos, ícones que constroem os processos identitários sendo que essas considerações ficam inteligíveis quando da exemplificação de determinados suportes culturais.Outras análises sobre a perspectiva da identidade territorial será vista em Milton Santos e Stuart Hall, Lobato Corrêa e Claude Raffestin críticos da globalização e teóricos sobre o território e os seus processos dinâmicos de transformação.

\section{Algumas definições de território e suas representações}

Antes de procurarmos entender as dimensões simbólicas do território e suas interfaces com a identidade, é preciso transitar por alguns conceitos, pois estes representam o movimento acadêmico, acerca de algumas concepções e reformulações da temática do território como pesquisa. Assim iremos notar que em algumas definições selecionadas aqui, estas apontam para o viés econômico do fenômeno da globalização e suas influências no processo de transformação social, as relações de poder, presentes no território e suas conflituosidades. Por outro lado o território também é interpretado do ponto de vista de suas dimensões simbólicas e afetivas, como a questão do pertencimento e a formação de processos identitários. Essas visões são refletidas com as discussões postas por geógrafos como Milton Santos, Lobato Corrêa, Haesbaert Costa e Claude Raffestin críticos da globalização e estudiosos dos conceitos sobre território, nessa perspectiva global que representa para ambos e que corroboram entre si alguns aspectos que delineiam uma série de aspectos nocivos à identidade do território pode ser observados quando discutem as dinâmicas territoriais nos processos de "territorializaçãodesterritorialização-reterritorialização" processo que discute amplamente 
e de modo interessante a gama de relações de poder, é conhecido pela sigla T-D-R. "O conceito de T-D-R foi postulado por Claude Raffestin para definir o território como conjunto de relações que se desenvolvem da interação entre espaço-tempo" (HAESBAERT COSTA, 1997).

Segundo Haesbaert Costa, a definição de território deriva do 'latim territorium' que é derivado de terra e que nos tratados de agrimensura apareceu com o significado de 'pedaço de terra apropriada'. Na geografia aparece com destaque no final dos anos de 1970. È interessante na citação a seguir, a reunião de conceitos e perspectivas sobre o território vejamos:

1) jurídico-política - definido por delimitações e controle de poder, especialmente o de caráter estatal; 2) a cultural(ista) - visto como produto da apropriação resultante do imaginário e/ou "identidade social sobre o espaço"; 3) a economia - destacado pela desterritorialização como produto do confronto entre classes sociais e da "relação capital-trabalho". O mesmo autor afirma que os mais comuns são posições múltiplas, compreendendo sempre mais de uma das vertentes (HAESBAERT COSTA, 1997, p. 3940).

O conceito de território para Haesbaert Costa vai além da compreensão do domínio e poder, focando também a perspectiva da dimensão simbólica e identitária, visão esta que se apoia na observância do espaço e o seu caráter de identidade social. Para Milton Santos esse processo de desterritorialização nada mais é do que a perda, reapropriação, criação e reconstrução, representando uma dinâmica paradoxal de transformação que sofre determinados espaços provocados pela globalização via capitalismo dentro de suas variáveis econômicas e que muitas vezes em nosso dia a dia tal compreensão desse processo de transformação do território devido sua dinamicidade nos é dificultado. Dessa forma a visão conceitual e interpretação do território por Milton Santos perpassam por questões como o seu domínio, as relações de poder presente na relação Estado-nação, o sistema econômico capitalista e o fenômeno da globalização cujos efeitos podem ser analisados, por exemplo, nas relações entre capital e trabalho, produção e espaço.

Essas visões conceituais são amplas, complementares e segundo Haesbaert Costa são importantes para adequar o território como pesquisa, seus diálogos e reflexões.

Ao dizer que o território pode ser entendido na ótica do pertencimento deste por um individuo ou grupo de indivíduos, Lobato Corrêa afirma suas concepções de território fundadas na dimensão identitária, corroborando com Haesbaert Costa para ampliar o diálogo para questões além da visão do poder. 
"perda do território apropriado e vivido em razão de diferentes processos derivados de contradições capazes de desfazerem o território", e a re-territorialidade como a "criação de novos territórios, seja através da reconstrução parcial, in situ, de velhos territórios, seja por meio da recriação parcial, em outros lugares, de um território novo que contém, entretanto, parcela das características do velho território (...)" (CORRÊA, in: SANTOS 1996, p. 252).

Assim os conceitos de desterritorialização e reterritorialização sinalizam para as dinâmicas territoriais no sentido das apropriações, perdas e novas reapropriações, conferindo um caráter dinâmico e complexo no jogo das relações de poder e de suas dimensões simbólicas como a questão da perda e criação. Essa compreensão estreita-se ao enquadrar determinados grupos identiários e suas relações entre si, seja de conflito ou amistosas, como exemplo desses grupos identitários podemos citar as comunidades quilombolas, os traficantes de drogas, comunidades ribeirinhas $\mathrm{e}$ eclesiásticas.

O espaço é, portanto palco de dimensões simbólicas e culturais que o transforma em território a partir de uma identidade própria criada pelos seus habitantes que o apropriam, não necessariamente como propriedade, mas com a ideologia-cultural manifestada nas relações políticas, sociais, econômicas e culturais. (SOUZA E PEDON, 2007, p.133).

É interessante a reflexão abaixo no sentido em que se observa a importância da ciência histórica e o seu conceito de temporalidade, como forma de entender os grupos identitários e os processos da T-D-R ao longo de conjunturas históricas, as quais se modificam continuamente, o que nos faz pensarmos na organicidade do território e o seu caráter subjetivo e intangível.

A dimensão da história no contexto da territorialização - dimensão espaço-temporalidade - se realiza na prática cotidiana dos grupos que estabelece vínculos com os de dentro e os de fora, os "nós" e os "outros", que dentro do plano do vivido, sentido, percebido e concebido, produz o conhecido e o reconhecido. (SOUZA E PEDON, 2007, p.132).

Observamos até aqui o movimento acadêmico em torno das concepções de território e suas diversas interpretações sejam no campo do domínio e das relações de poder e imbricado com a questão da identidade e em suas múltiplas interfaces como as dimensões simbólicas, as quais constitui uma lógica de constituição e explicação dos territórios como a ideia de simbologia que cria códigos, valores e que estes estão de modo complexo materializados em nosso cotidiano. A seguir essas questões ficaram um pouco mais exemplificadas, sobretudo com o conceito de Clifford Geertz e suas ideias de significação desses símbolos. 


\section{As dimensões simbólicas, culturais e identitárias do território}

No livro a "Interpretação das culturas", Clifford James Geertz analisa, interpreta e estabelece uma abordagem dos fenômenos culturais na ótica da simbologia, ou seja, para ele o universo da cultura forma um sistema simbólico que considera a cultura um conjunto ordenado de símbolos e signos com significados transmitidos e incorporados historicamente nas sociedades, a partir de códigos, leis, tradições, imposições, apropriações e reapropriações, frente ao jogo das relações de poder entre as distintas classes sociais. Para Geertz tais símbolos assim refletem as produções culturais. Suas orientações teóricas e metodológicas como antropólogo centram-se na linha etnográfica na qual a ação do homem nos campos da arte, religião, ciência e leis é o ponto crucial de onde parte suas reflexões e considerações sobre o aspecto cultural que ele denomina de situações concretas. Segundo Geertz são nestas situações que residem às particularidades e o entendimento do sentido das situações.

Tomamos como exemplo de símbolo os comportamentos analisados como as folias de reis do sertão baiano, onde determinados grupos vestem trajes típicos paramentados, carregam um estandarte que representa as concepções do grupo, irmandade, tocam instrumentos, cantam, dançam e fazem orações. Esse grupo andante transita por entre ruas e casas, onde são recebidos tradicionalmente por moradores que são fieis a tradição num espírito de lealdade, respeito, fé, e alegria. jAo final de cada rito de passagem os foliões são agraciados com uma pequena ceia. Assim a folia de reis no seu conjunto de tradições, representações, carrega significados em cada um de seus detalhes, há nas entrelinhas dessa significância, um ritual coeso, rígido a exemplo de hierarquias dos participantes e a escolha de grupos, bem como a escolha do folião que será o guardião do estandarte para o próximo ano, o que pode está relacionado a um código e tradição conforme interpreta Geertz.

Nessa linha de pensamento diferentes símbolos ou produtos culturais são passíveis de serem enquadrados e interpretados como uma manifestação que representa códigos, tradições, leis,como as diferentes concepções de partidos arquitetônicos, o modo de fazer requeijão, uma panela de barro, uma cesta de palhas, entre outros diante da enorme grandiosidade que o campo da cultura nos oferece e que podem ser associados a 
comunicam-se, perpetuam-se, desenvolvem seu conhecimento sobre a vida e define sua atitude em relação a ela" (GEERTZ, 1978, p.36).

É interessante salientar que o conceito de apropriação e reapropriação afirmado por Geertz imerso na ótica da simbologia e logo na dinâmica das representações simbólicas da cultura, trazem aspectos que nos informa sobre as suas transformações, resistências perante o jogo de poder que está presente no cotidiano com relação às manifestações em determinados territórios, seja por condições geográficas, religiosas e econômicas.Assim o que torna o território uma possibilidade de análise enquanto dimensão simbólica da cultura é o entendimento da lógica da construção do universo da cultura, pautado pelas diferentes produções culturais como já citadas anteriormente.

O desafio de compreender o mundo em que se colocam os
geógrafos requer também considerar a força dos símbolos, das
imagens e do imaginário (...) o domínio do simbólico possui um
inegável valor explicativo. (...) Apesar da racionalidade moderna
ter conquistado os espaços objetivos das relações sociais, as
representações permanecem nos dispositivos simbólicos, nas
práticas codificadas e ritualizadas, no imaginário e em suas
projeções (CASTRO, 1997, p. 156).

Como se vê nos dizeres de Castro Elias o domínio do simbólico é complexo, é algo que nos teremos que identificar e decifrar em meio a suas projeções na sociedade, mais que é plausível dado o seu caráter explicativo. Ao exemplificamos acima as folias de reis no território do Alto Sertão da Bahia, como uma espacialidade que selecionamos pela sua interessante formação histórica e pelo nosso interesse em historiografar em nossas pesquisas esse espaço e suas manifestações culturais, observamos essa complexidade enquanto práticas que possuem códigos e rituais, os quais enraizados no imaginário daquelas sociedades cujas expressões apresentam um caráter intangível e complexo. Recentemente foi lançada pela Superintendência de Estudos Econômicos e Sociais da Bahia - SEI e pela Secretaria da Cultura - SECULT do governo da Bahia a publicação: "Panorama Cultural da Bahia Contemporânea", estudo que contempla uma série de dados culturais no Estado,abrangendo diversas macrorregiões em sua dimensão continental que recebe a denominação de regiões socioculturais. Em sua parte IV que trata da região sudoeste do Estado e mais especificamente concentrando-se a leitura no texto: "Exterioridades culturais contemporâneas do Alto Sertão da Bahia e do Sertão da Ressaca" (SEI, 2012, p. 191-228) organizado pelos historiadores Erivaldo Fagundes Neves (importante historiador sobre o sertão baiano) e Caio Figueiredo Fernandes Adan, é possível vislumbrar a conjuntura social do Alto Sertão baiano e verificar importância das influências políticas, sociais e econômicas em sua conjuntura geral, como 
a formação e influência dos núcleos centralizadores que constituíram importantes cidades e suas dinâmicas culturais.

Permeado por essa lógica do espaço simbólico, produto de uma construção histórica, é preciso neste processo de análise congregar algumas interfaces que o campo da cultura e logo suas produções culturais nos oferece. Nesse sentido é interessante analisar a interface da identidade que está associada ao conceito de cultura num processo de formação e constituição de dinâmicas culturais, da própria noção de Estado-nação. O termo identidade deriva do latim e nos remete ao que é idêntico e exclusivo numa relação entre o individual, coletivo, suas particularidades e diferenças. Não por acaso e com muita frequência os estudos sobre identidade cultural tem ganhado destaque em uma série de trabalhos, sobretudo no campo das ciências sociais sobre aspectos culturais e políticas culturais associados, por exemplo, ao fenômeno da globalização da economia. Segundo Denys Cuche "a recente moda da identidade é o prolongamento do fenômeno da exaltação da diferença que surgiu nos anos setenta, contexto que engendrou a apologia da sociedade multicultural" (CUCHE, 2002, apud PITOMBO, p.7).

A interface entre cultura e identidade é uma relação tão próxima, inseparável que o estudo da identidade cultural está entrelaçado aos objetivos de diversas ciências, como a antropologia, sociologia, história entre outras na busca por entender o homem e a sociedade, sendo discutida na teoria social, cujas fluências epistemológicas enriquecem e dinamizam o conceito, aspectos e importância da reflexão sobre as dimensões da cultura na sociedade.

\footnotetext{
A territorialidade ao mesmo tempo em que expressa a luta pela manutenção da identidade, representa uma forma especifica de ordenação territorial. Pois uma coisa está imbricada na outra de forma a dar unidade aos contrários que dão movimento ao processo da formação das identidades territoriais (SOUZA E PEDON, 2007, p.135)
}

Com a tradição dos estudos da Escola dos Annales desde o início do século XX, a ciência histórica tem gerado uma legião de historiadores da cultura, quando a disciplina foi problematizada e o jargão "tudo é história" passou a ocupar de forma mais intensa estudos na perspectiva da cultura que emana em diferentes sociedades, tendo como protagonistas determinados grupos de indivíduos, que por vez estão inseridos numa espacialidade, em um cotidiano que se renova a partir da individualidade, seja de gênero, de condição social e econômica, para constituir uma coletividade que se expressa, por exemplo, na cultura e que por séculos fora marginalizado. Assim dentro das áreas de abrangência da ciência histórica a perspectiva da história cultural na atualidade é 
objeto de estudo dos historiadores que se preocupam com uma série de questões, dentre elas a interface da identidade como conhecimento, como retórica para reflexão e preservação de símbolos culturais e suas dinâmicas, dimensões e de sua natureza diante da diversidade da cultura, como suas contradições entre cultura erudita e popular.

Assim o autoconhecimento, consciência e senso crítico dos indivíduos sobre os significados de sua produção perante as outras realidades de produções culturais são fundamentais no processo de valorização e preservação onde a diversidade e identidade seria assim uma sinergia que alimenta os estudos, seja com as questões relacionadas às ameaças à preservação e também à fruição dos bens culturais intensamente debatidos atualmente, cujos problemas originam do fenômeno da globalização, onde suas influências têm alavancado tais estudos, como a Declaração Universal dos Direitos Humanos, na Declaração da Diversidade Cultural, e recentemente na Convenção para Promoção e Proteção da Diversidade das Expressões Culturais. Por outro lado e como veremos a seguir, quando da ausência de senso crítico por parte do individuo perante as relações entre produção, valorização, consumo, fruição dos bens culturais, seja no sentido em que há a realidade de diferentes produções culturais e logo uma diversidade, de que todo produto, manifestação possui uma identidade cultural que compete a outras identidades, entre territórios e indivíduos, dessa maneira um território corre o risco de fragmentação em detrimento de outro sofrendo intensas transformações.

Estudo interessante que foca a identidade cultural com parâmetro de análise sobre suas transformações sociais e logo dos indivíduos é a obra: "A identidade cultural na pós-modernidade" escrita pelo sociólogo Stuart Hall que trabalha com as concepções: "sujeito do iluminismo"; "sujeito sociológico" e "sujeito pós-moderno" que analisaremos a seguir. $\mathrm{O}$ argumento geral de Hall gira em torno da ideia que as velhas identidades que por muito tempo foram aspecto de coesão social como de gênero, classe, etnia, religião, nacionalismo, são aspectos que entraram em declínio provocando a chamada "crise de identidade", fazendo emergir novas identidades e fragmentado o individuo moderno. Em suas análises são utilizados conceitos como: "descentração do sujeito, identidades deslocadas e fragmentadas" contribuindo sobremaneira para o estudo das transformações sociais sobre diversos prismas, sem encerrar o conceito de identidade que é complexo por ser novo, Hall acaba por se perguntar "será que não é a própria modernidade quê está sendo transformada”? (HALL, 2006, p.10). Para Hall o importante é que em nossas reflexões sobre a formação da identidade a estratégia da identificação de que sua lógica gira em torno de um processo sistemático 
e em andamento e não ao contrário sendo encarado com um processo acabado.

A análise de Stuart Hall fundamenta parte dessa lógica com as relações descritas acima, consequência de uma abstração, que gera a desvalorização, descaracterização e até mesmo destruição de elementossímbolos de sua produção cultural, afetando sobremaneira uma determinada identidade cultural, que provoca a chamada quebra, crise cultural ou de identidade. Essa lógica de estudo em Hall centra-se em uma análise histórica dos sujeitos, que num primeiro momento Hall identifica um tipo que ele denomina de "sujeito do iluminismo" em alusão a uma característica de "um individuo centrado, unificado, dotado das capacidades de razão, consciência e de ação cujo centro constituía em núcleo interior", (HALL, 2006, p.10) onde o traço característico que marca esse indivíduo é sua identidade essencialmente individualista. Esse tipo de sujeito é moldado e fragmenta-se para se transformar segundo Hall em "sujeito sociológico”, ou seja, surge um novo tipo de individuo cuja identidade vai se constituindo a partir de uma relação com outros sujeitos "numa interação entre o eu e a sociedade" (PITOMBO, 2013, p.8), assim o "sujeito do iluminismo" fragmenta-se no sentido em que a individualidade o restringe de ser autônomo, como o "sujeito sociológico".

Percebemos nessa evolução entre as concepções de sujeito e suas identidades o quanto a cultura é um processo em metamorfose contínua, que dinamiza, quebra padrões, cria novos paradigmas e a torna cada vez mais complexa as sociedades marcadas pela diversidade que a moderniza. Na atualidade Hall percebe que há uma predileção ao "sujeito pós-moderno" que surge das intensas transformações via globalização, do tudo rápido proporcionado pela alta tecnologia da informação, criando assim outras identidades culturais bem mais complexas, no sentido em que a própria gama de variedades de processos de produção cultural acaba por criar uma identidade cultural que foge de um padrão rígido, unificado, mas sim constituindo processos e relações instáveis, é aí que se encontra o "sujeito pós-moderno" aquele diverso, complexo, emergido num sociedade que se renova de maneira veloz e o molda um sujeito que pode ser associado a várias identidades, correspondendo muitas vezes a uma relação paradoxal e conflitual.

O sujeito pós-moderno, conceptualizado como não tendo uma identidade fixa, essencial ou permanente. A identidade torna-se uma celebração móvel: formada e transformada continuamente em relação às formas pelas as quais somos representados ou interpelados nos sistemas culturais que nos rodeiam. (HALL, 2006, p.13). 
Com ajuda de Hall percebemos que esse "sujeito pós-moderno" de várias identidades vem gerando a chamada "descentração dos sujeitos" criando assim uma série de ameaças tais como: dificuldade de se reconhecer como sujeito histórico em sua própria cultura em meio a essa diversidade, entre outros problemas de crise de identidade identificados por Hall.

Podemos identificar que a questão da identidade entra em crise quando observamos a própria fragmentação da prática cultural por diferentes motivos, como o paradigma conflitual entre indústria e artesanato, tradição e modernidade, dos ofícios de mão de obra tradicional ligados a uma economia sustentável e criativa para processos de exclusão social e mercadológica que são paulatinamente substituídos por ações pautadas pelo avanço tecnológico, como exemplo, citamos a quase extinção do artesanato em barro das tradicionais feiras das pequenas cidades no Alto Sertão da Bahia, em detrimento de outros materiais como ferro. Dessa realidade aparece o conceito deresistência cultural no sentido de entender as mudanças de paradigmas históricos entre as velhas e novas identidades presentes nas dinâmicas territoriais que se aceleram sob o ritmo do sistema capitalista a partir de uma conjuntura global, onde se torna imprescindível à análise do fenômeno da globalização que como já dito deverá ser objeto de análise obrigatório em estudos sobre os fenômenos como "crise de identidade", "fragmentação das unidades e a descentração de sujeitos"(HALL, 2006, p.07-10). A partir dessas ideias procuramos entender o lugar da identidade cultural e da concepção de um território perante a uma realidade global e seus significados no presente e para o futuro da sociedade na qual se insere.

Vivemos a realidade de um mundo globalizado, onde segundo Hall a quebra de fronteiras, a diminuição das dimensões entre tempo-espaço, vem provocando impactos como "homogeneização cultural $e$ desintegração das identidades" (HALL, 2006, p.69), ou seja, a quebra do que Hall chama de "unidade sólida" ou simplesmente, coesão, rigidez. Concordamos com esse posicionamento, pois o caráter das informações instantâneas geradas pelas tecnologias, seu caráter volátil, onde a ideia de evolução e progresso permeado pelas políticas modernistas, desenvolvimentistas e progressistas na maioria das vezes não contemplam em nosso ver a preservação de símbolos culturais portadores de nossa identidade, daí enxergamos em nosso cotidiano a mudança dos traços urbanísticos, a arquitetura vernácula das pequenas cidades quando são impactadas por projetos contemporâneos importados, ou seja, a entrada de concepções e outras experiências culturais importadas, ou seja, de "identidades deslocadas" muitas delas estranhas à cultura local, 
frente, por exemplo, ao progresso das grandes metrópoles que imprimem essas experiências e influências modernistas e contemporâneas.

As relações entre o binômio "Política Cultural" e "Produção Cultural", em parte nos auxilia como termômetro na compreensão de aspectos como a produção, reprodução, preservação, eminência de descontinuidade histórica e extinção ao universo dos bens culturais, suas representações, sua interlocução com a economia criativa no viés da sustentabilidade, as quais sinalizam as preocupações entre o conhecer e preservar perante a esse conjunto de transformações identificadas em parte por Hall em sua discussão sobre declínio de "velhas identidades", "descentraçao dos sujeitos" e por vez a "desintegração de identidades" até então sólidas, como se ver em seus símbolos, ícones socioculturais. Partilhamos das ideias de Hall no sentido em que elas nos auxiliam em identificar e interpretar problemas de diversas naturezas no campo cultural eles, as questões econômicas capitalistas, a globalização e suas influências a exemplo da produção em série, do turismo predatório, das orientações religiosas e filosóficas, as concepções e relações do homem como o meio ambiente, o papel do ensino e das pesquisas, os conflitos entre indústria e artesanato, tradição e modernidade e preservação e desenvolvimento, questões estas constantemente vivenciadas por nós em nosso cotidiano e que se configuram como problemas que ameaçam a preservação das manifestações culturais em suas diferentes naturezas.

\section{Considerações finais}

Como visto aqui e em parte, a ideia de identidade tem sido um tema recorrente no universo da cultura, uma vez que identidade e cultura estão fortemente associadas e como tal aplicam-se perfeitamente as questões que se correlacionam ao território. A diversidade de temas e suas identificações podem ser vislumbradas a partir do conjunto de estudos em diferentes concepções ideológicas como as ideias de Clifford James Geertz que foram utilizadas para falar da simbologia e do sistema de significações de determinados suportes culturais. Observamos o debate em torno do conceito antropológico de cultura entre Laraia que tece críticas ao pensamento de Taylor. Em Hall vimos à importância de suas indagações a respeito da identidade quando analisa o tema e seus rumos na pós-modernidade, analisando a "crise de identidade", "descentração dos sujeitos" "fragmentação, homogeneização cultural e desintegração das identidades". Em Haffestin, Milton Santos, Lobato Corrêa, ancorados na ciência geográfica analisamos os conceitos de "territorialização- 
desterritorialização-reterritorialização" no âmbito dos debates e críticas em torno das influências do processo de globalização.

Dessa maneira o artigo apresenta alguns dos múltiplos e complexos conceitos e dimensões em torno da tríade território-cultura-identidade e suas interlocuções ao campo das questões de território. Reconhece-se a diversidade e multidisciplinaridade em diversas contribuições das ciências sociais, as quais se juntam a ciência geográfica, cujos estudos tradicionais trabalham com a temática do território, o que lhe é própria, a lançar olhares sobre questões como a ideia de domínio e no campo das relações de poder via globalização. Com estas reflexões nota-se a importância e apreço dessa temática para a compreensão e as discussões na atualidade perante o conjunto de políticas culturais com o objetivo de abordar a perspectiva do território em suas dimensões simbólico-culturais e identitárias, as interfaces que o conceito e o campo da produção cultural apresentam à sociedade, refletindo assim a gama de questões como: imaterialidade e materialidade, identidade, das quais fundamentam o entendimento sobre a lógica da produção cultural, suas demandas, limites e problemas como o do desenvolvimento da política cultural e sua relação direta, por exemplo, com a preservação.

Assim diferentes grupos identitários poderão ser enquadrados em diferentes territórios e suas respectivas lógicas como o campo das relações de poder. As produções culturais são símbolos da cognição humana, sua diversidade e complexidade podem gerar limites em sua identificação, e discussão em suas dimensões na sua historicidade, seus processos identitários presentes nas relações de poder em seu cotidiano. É preciso levar em conta que tal complexidade encontra-se no caráter de sua intangibilidade, a qual não comporta padrão, receita, mas reflexões, e sempre deixando em aberto para considerações futuras. A identidade cultural como visto emerge de grupos sociais, onde os aspectos da individualidade e da coletividade jamais podem ser dissociados, pois é uma condição inerente ao homem com algo que é construído, reconstruído e recaem constantemente sobre determinados pontos de referência seja para nossa condição existencial ou como individuo que pertence a um determinado espaço, identidade-nação.

Essas concepções e possibilidades de análises e suas discussões sobre as políticas culturais se processam numa dimensão que podem como visto partir de uma visão macro, do global para o local, buscando assim contextualizar parte do universo da cultura em uma determinada sociedade, a partir desse panorama da evolução, conceituação e enquadramento das interfaces das dimensões simbólicas da cultura, produção, do território como espaço abrangente, aqui apresentado, nos 
oferece parâmetros para compreendemos em parte o universo dos estudos culturais, seus rumos e importância enquanto área setorial e como política de Estado, os especialistas em políticas culturais cada vez mais nos chama atenção para a questão da produção e preservação cultural, pontuando que as políticas devem ser de Estado e não de governo as quais muitas vezes, estão carregadas de pessoalidade e desconexões de temporalidade, daí observa-se a instabilidade de projetos devido a trocas de governos dentre tantas outras ideias debatidas.

Pensamos que essa discussão possa contribuir para o debate sobre a importância do território como pesquisa e suas questões pertinentes como a importância das pesquisas sobre o espaço como detentor de dimensões simbólicas, culturais e identitárias. Fazemos assim as seguintes indagações: Qual o papel e como caminham as políticas territoriais? Qual o papel do território na perspectiva de políticas culturais?A compreensão e harmonia entre as políticas territoriais e culturais são possíveis? Elas poderão salvaguardar os bens culturais simbólicos de diversas naturezas? Penso que em parte os resultados desta pesquisa encontram-se na reflexão sobre o território em outros prismas.

\section{Referências}

CASTRO, Iná Elias de. Imaginário Político e Território: natureza, regionalismo e representação. In CASTRO, Iná Elias et. al.. Explorações Geográficas. Rio de Janeiro: Bertrand Brasil, 1997.

CORREAA, Roberto Lobato. Territorialidade e Corporação: um exemplo.In SANTOS, Milton et. Al.(org.) Território:Globalização e Fragmentação. $3^{a}$ ed. São Paulo: HUCITEC, 1996, p. 251-256.

COSTA, Rogério Haesbaert. Des-territorialização e identidade: a rede "gaúcha" no nordeste.Niterói: EDUF, 1997

ELIAS, Norbert. O processo civilizador (vol.1). Rio de Janeiro: Jorge Zahar, 1994.

GEERTZ, Clifford. A Interpretação das Culturas. Rio de Janeiro, Zahar.

HALL, Stuart. A identidade Cultural na pós modernidade. Trad. Tomaz Tadeu da Silva, 2 ${ }^{\mathrm{a}}$ Ed. Rio de Janeiro: DP\&A, 2006. 
LARAIA, Roque de Barros. Cultura: um conceitoantropológico. 13. ed. Rio de. Janeiro: Paz e Terra, 1986.

PITOMBO, Mariela. O campo da cultura. In: Curso Gestão de empreendimentos e gestão de projetos culturais. MINC/SENAC, 2013.

RAFFESTIN, Claude. Por uma Geografia do poder. São Paulo: Ática, 1993.

SOUZA, Edvaldo Aparecido; PEDON, Nelson Rodrigo. Território e Identidade.Revista Eletrônica da Associação dos Geógrafos Brasileiros - Seção Três Lagoas - MS, V 1 - n. ${ }^{\circ} 6$ - ano 4, Novembro de 2007.

Superintendência de Estudos Econômicos e Sociais da Bahia/Secretaria da Cultura. Panorama cultural da Bahia. - Salvador: SEI/SECULT, 2012.

TEIXEIRA, Coelho (org). Dicionário Crítico de Política Cultural: Cultura e Imaginário. São Paulo: Iluminuras, 1997. 